\title{
Manager's Rent and Corporate Investment
}

\author{
Junhe Zhang \\ Department of Applied Economics \\ Nanjing University of Science and Technology \\ Nanjing, China \\ 791927341@qq.com
}

\begin{abstract}
This paper wants to figure out how the pandering between the manager and shareholder groups affect corporate investment and how regulations work on it. Using the pork model, we can find that the pleasing behavior of the manager will surely lead to overinvestment and regulations that solve this problem would lead to another type of inefficiency.
\end{abstract}

Keywords-shareholder groups; inefficient investment; regulation; manager's rent

\section{INTRODUCTION}

In the research of companies' investment decisions, the manager should always distribute his investments based on the optimal path for himself. This path or strategy is some kind of choice based on a fundamental rule. Given this rule or mechanism, we can derive the specific result of an allocation. In a discrete allocation, the discount value based on those projects the manager chose should dominate all other options.

The payoff of the manager depends on the power for allocation, which usually determines the characteristics of personal welfare. In some companies, the manager has his own estimation on the company's future, once he realizes that the development may be limited, he may choose a "hit and run" strategy, which means he will choose the projects with high personal payoff in the short term. After this, he will sell all his shares and then resign. This is not rare in the companies whose real growth potential cannot afford the expectations of the public after too much capital have been raised. But if the market of managers is highly efficient, the manager will have to consider all the consequences that will influence the price for him in the future market of managers. So as opposed to the first circumstance, an option shall be that the manager concerns about the specific "bidder" and he will use investment behavior to show this kind of concern for a better payoff in the future [1] Those bidders who are in the manager's concern should be those who can determine whether the manager could extend as incumbent and could at least keep the level of payoff, such as substantial shareholders and interest groups. If the propensity of spending is unknown at the beginning, the manager should at least show a signal of cooperation by choosing investment projects that will be most beneficial to specific groups of substantial shareholders.

The subsequent analysis will assume that the preference and investment propensity of the manager among different groups of shareholders is unknown to others, or at least most shareholders lack of decisive information about how the manager will make the investment decision and how this decision will lead to inefficiency. This paper will follow the framework of Maskin\&Tirole [2], which showed a typical condition for political pork, to analyze the relation between the manager and groups of shareholders and how this relation could bring inefficiency to the whole company. We can apply the framework with regulations settled by China Securities Regulatory Commission by introducing a relative regulatory mechanism which the manager should always consider the personal cost of pleasing some groups of shareholders. If his propensity is known to all, he may lose his chance in the market of managers and get punished by the regulatory commission. Sometimes the regulation may lead to another kind of inefficiency because of the manager's priority of investment projects. The manager avoids the limitation by giving up some good investments.

\section{ANALYSIS}

\section{A. Overinvestment without regulations}

We assume that time is discrete, the manager will make his investment decision in the first period, and a continuum of groups of shareholders is under uniform distribution on $[0,1]$. In the first period the manager will choose a level of project for each group $X_{i} \in\{0,1\}$, project $X_{i}=1$ will generate $B$ to shareholder group $\mathrm{i}$ and will cost $\mathrm{C}$ to the shareholders as a whole. When $X_{i}=0$, there is no revenue and no cost. The payoff for group i should be

$$
X_{i} B-C \int X_{j} d j
$$

In which $\mathrm{j} \neq \mathrm{i}$

The manager will always need to please some specific groups of shareholders because they have more power in determining future welfare. As a result, the manager will put a weight $a_{i}$ for group $i$, and $a_{i}$ will increase in i. Outsiders won't know the distribution of $a_{i}$ until the investment is made. The utility function of the manager in the first period will be

$$
U(X)=\left(\int_{0}^{1} a_{i} X_{i}\right. \text { di) B - XC }
$$

There will be a threshold level for a project, those $X_{i}$ which are larger than this level shall be 1 , and others shall be 0 . Let $\mathrm{F}(\mathrm{a})$ be the proportion for those groups who have $\mathrm{a}_{\mathrm{i}} \leq a$, then

$$
\mathrm{U}(\mathrm{X})=\mathrm{X}\left[\left(\int_{q}^{\infty} \text { a } \mathrm{F}(\mathrm{a}) / 1-\mathrm{F}(\mathrm{q})\right) \mathrm{B}-C\right]
$$$$
\text { In which } \mathrm{q}=\mathrm{F}^{-1}(1-\mathrm{X})
$$ 
When the manager choose an allocation $\mathrm{a}^{*}$ such that $\mathrm{a} * \mathrm{~B}=\mathrm{C}$, and when there is no regulatory commission, the manager will invest for those who satisfy $\mathrm{a}_{\mathrm{i}} \geq \mathrm{a}^{*}$,and thus we have the allocation $\mathrm{Y}=1-\mathrm{F}\left(\mathrm{a}^{*}\right)$.

To let the regulation work, we shall assume that $\mathrm{Y}<\frac{1}{2}$, or the manager will please more than half of the groups if not so.

As we mentioned, if the market of managers is highly efficient, then once the manager fails to please those shareholders groups who can determine whether he could keep his job, he will be replaced soon enough. Those groups will choose a challenger to put a new allocation, under the assumption that the distribution of groups will never change, this screening process will repeat. The welfare for the incumbent will be

$$
\mathrm{V}=\mathrm{U}(\mathrm{X})+\mathrm{P}(\mathrm{X}) \mathrm{R}
$$

Where $\mathrm{P}$ denotes the probability that the incumbent will extend his job when a investment allocation $\mathrm{X}$ is made, $\mathrm{R}$ denotes the rent for the manager when the job is extended. $R$ comes from two points, one is that the manager himself could get a part of profit from the groups he pleased as personal payoff, and the remaining part should be the rent for the power of decision-making.

Consider a condition that the investment behavior is highly sequential, if the regulatory commission is able to find the propensity of the manager from sequential behaviors, then the manager will need to worry about a personal cost. For some reasons like this, the manager will choose an investment allocation $\mathrm{X}$ that differs from $\mathrm{Y}$ (the allocation $\mathrm{Y}$ is known to shareholders). So Y could be deemed as the probability that the specific group will gain a profit once the manager is reelected.

Suppose $\mathrm{X}>\mathrm{Y}$, then the groups will modify their expectations $\mathrm{Y}^{\prime}=\frac{Y}{X}$. When there is no audit and regulation, the manager will choose $\mathrm{X}=\mathrm{Y}$, no adjustment is needed. Because $\mathrm{R}>\mathrm{U}(\mathrm{X})-\mathrm{U}\left(\frac{1}{2}\right)$, so $\mathrm{X}=\frac{1}{2}$ should be a threshold level, at this level the manager could keep his job. When $\mathrm{X}=$ $\frac{1}{2}$, the probability that the manager would successfully please the groups he need $\mathrm{Y}^{\prime}=\mathrm{Y} / \frac{1}{2}=2 \mathrm{Y}$, the payoff in next period will be $\mathrm{Y}(2 \mathrm{~B}-\mathrm{C})$. If the manager is replaced, then the payoff will only be $\mathrm{Y}(\mathrm{B}-\mathrm{C})$. As a result, the manager will at least keep his job at a level $\mathrm{X}=\frac{1}{2}$.

When there is no outside regulation, $\mathrm{X}=\mathrm{Y}$, the manager will choose the same allocation in any periods, which will surely lead to overinvestment in some projects for the company. There is a scenario in reality that some shareholders may have consensus interest but it won't show at a group level that will influence the manager's job, which means at least some shareholders don't show their choice with strong correlation with the manager's investment behavior. They may choose some other rule to make their choice such as the long-term development of the company or manager's personal ability to manage all the businesses. Another situation could be that the distribution of welfare within a specific group may not equal the power of election among shareholders.

Suppose there is a fraction $\delta_{\mathrm{i}}$ in group $\mathrm{i}$ who will choose the manager based on the investment decision of the manager in period 1, and the remaining shareholders will make their choice based on some characteristics unrelated to the policy in the first period. Under such condition, if there will be a random fraction $\varphi$ who will vote for the manager regardless of the investment allocation, we can write the necessary condition for the manager to keep his job as

$$
\int \delta_{\text {i. }} \mathrm{X}_{\mathrm{i}} \mathrm{di}+(1-\delta) \varphi \geq \int \delta_{\mathrm{i} .}\left(1-\mathrm{X}_{\mathrm{i}}\right) \mathrm{di}+(1-\delta)(1
$$
- $\varphi)$

Let $\mathrm{H}$ be the cumulative distribution of $\varphi$ and $\mathrm{h}$ be its density, and thus

$$
\mathrm{P}(\mathrm{X})=1-\mathrm{H}\left(\frac{1}{2}+\left(\int \frac{1}{2} \delta_{\mathrm{i}}-\mathrm{X}_{\mathrm{i}} \delta_{\mathrm{i}}\right) /(1-\delta)\right)
$$

Only when

$$
\mathrm{a}_{\mathrm{i}} \mathrm{B}-\mathrm{C}+\frac{h}{1-\delta} \delta_{\mathrm{i}} \mathrm{R}>0
$$

could the specific groups be beneficiaries. It shows the influence of random voting in a group which maximizes its payoff by pork. From the inequality, we can see that the probability that the manager would successfully have a deal with specific groups depends on $\mathrm{R}$, which is the manager's rent. When the rent increases, the inequality is more likely to be satisfied thus both the manager and the specific groups of shareholders will get the surplus.

If the groups want to maintain their position in influencing the manager, they should at least keep some level of $\delta_{\mathrm{i}}$ to show to the manager that his decision will not be in vain. Sometimes this kind of "common good" within one group is hard to maintain thus the result of the allocation may fluctuate from the equilibrium path..

\section{B. Inefficient investment under regulations}

In this framework, another problem needed to be considered is that how will the mechanism of regulation work on the manager. Just as the analysis above, if there is no audit and regulation, the manager will always choose the same investment allocation, thus a direct consideration of mechanism design should be a limitation on the investment [3]. This limitation could either be a constraint on the financing approaches which the manager chooses or a cap on the total amount of corporate investment. The first approach is based on free cash flow theory.

In a more realistic environment, to support such regulations, there will be a great need of financial information. Unfortunately, all this information could be twisted by the manager to cover his scheme [4-5].A typical approach is to use 
off balance sheet items, which could increase the cost and difficulty to dig the actual information.

Even though the regulator won't derive every detail about the manager's investment preference, he can still have a relative estimation on $\mathrm{X}$ the manager has chosen and use this estimation to set a limitation $\mathrm{L}$ on the total amount that the manager could invest. We assume there is no veto power [6].

What the manager should consider is that how to distort the information about $\mathrm{X}$ by some accounting tricks under a given $\mathrm{L}$. This distortion will twist the efficiency of financial reporting and cause a dead weight loss $\mathrm{D}_{1}$ to the whole company. Let $\mathrm{C}^{*}$ be the cost after the manager distort the accounting information, total cost shall be

$$
\mathrm{X}\left[\mathrm{C}^{*}+\mathrm{D}_{1}\left(\mathrm{C}-\mathrm{C}^{*}\right)\right]
$$

As mentioned before, the manager will keep his job when

$$
\int \delta_{\mathrm{i}} \mathrm{X}_{\mathrm{i}} \mathrm{di}+(1-\delta) \varphi \geq \int \delta_{\mathrm{i} .}\left(1-\mathrm{X}_{\mathrm{i}}\right) \mathrm{di}+(1-\delta)(1-\varphi)
$$

Let $\mathrm{l}_{0}$ be the optimal level of investment for the company, $\mathrm{W}$ denotes the welfare under this level, $\mathrm{D}_{2}$ denotes the cost for deviating from this level, thus the welfare from the actual investment $l$ can be written as

$$
\mathrm{W}-\mathrm{D}_{2}\left(\mathrm{l}_{0}-\mathrm{l}\right)
$$

The manager should solve the investment allocation problem $\operatorname{Max}\left\{\int \mathrm{a}_{\mathrm{i}} \mathrm{X}_{\mathrm{i}} \mathrm{B} \mathrm{di}-\left[\mathrm{X}\left[\mathrm{C}^{*}+\mathrm{D}_{1}\left(\mathrm{C}-\mathrm{C}^{*}\right)\right]+\mathrm{l}\right]+\mathrm{W}-\mathrm{D}_{2}\left(\mathrm{l}_{0}-\right.\right.$ l) $\left.+\left[1-\mathrm{H}\left(\frac{1}{2}+\left(\int \frac{1}{2} \delta_{\mathrm{i}}-\mathrm{X}_{\mathrm{i}} \delta_{\mathrm{i}}\right) /(1-\delta)\right)\right] \cdot \mathrm{R}\right\}$

S.t $1+\mathrm{X} \mathrm{C}^{*} \leq \mathrm{L}$

In which $\lambda$ denotes Lagrange multiplier for the inequality, we have

And

$$
\mathrm{D}_{1}{ }^{\prime}\left(\mathrm{C}-\mathrm{C}^{*}\right)=\mathrm{D}_{2}{ }^{\prime}\left(\mathrm{l}_{0}-1\right)=1+\lambda
$$

$$
\mathrm{a}_{\mathrm{i}} \mathrm{B}+(\mathrm{h} \delta \mathrm{R} / 1-\delta) \geq \mathrm{C}^{*}+\mathrm{D}_{1}\left(\mathrm{C}-\mathrm{C}^{*}\right)+\lambda \mathrm{C}^{*}
$$

We take the derivative of the right side

$$
\frac{d C *}{d L}\left(1+\lambda-\mathrm{D}_{1}{ }^{\prime}\right)+\mathrm{C}^{*} \frac{d \lambda}{\mathrm{d} L}
$$

If $\mathrm{L}$ increases, $\lambda$ would decrease, $\mathrm{C}^{*}$ would also increase on $\mathrm{L}$, thus we can conclude when $\mathrm{L}$ increases, the inequality above will be easier to be satisfied and we have

$$
\frac{d X}{d L}>0
$$

From this we can conclude that when the regulator enforces a loose limitation for investment, the manager will have more incentives to make overinvestment decisions. And when this limitation becomes looser, the efficient part of investment at a corporate level will also increase, which means a cap on this may lead to inadequate investment when the manager wants to keep his job but at the same time afraid of being punished for the pandering to some groups of shareholders.

The manager's main profit from his pleasing behavior is the rent $\mathrm{R}$, which drives the manager in the pandering process. Let $\mathrm{l}+\mathrm{X} \mathrm{C}^{*}=\mathrm{L}$ and $\mathrm{h}^{\prime}=0$, we can rewrite the objective function as

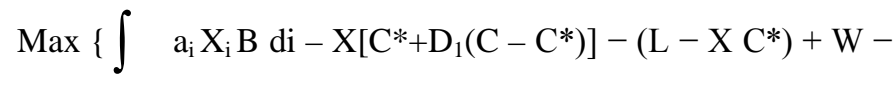

$\left.\mathrm{D}_{2}\left(\mathrm{l}_{0}-1\right)+\left[1-\mathrm{H}\left(\frac{1}{2}+\left(\int \frac{1}{2} \delta_{\mathrm{i}}-\mathrm{X}_{\mathrm{i}} \delta_{\mathrm{i}}\right) /(1-\delta)\right)\right] \cdot \mathrm{R}\right\}$

Thus like we analyzed before, the first-order condition can be written as

$$
\mathrm{D}_{1}{ }^{\prime}\left(\mathrm{C}-\mathrm{C}^{*}\right)=\mathrm{D}_{2}{ }^{\prime}\left(\mathrm{l}_{0}-\mathrm{L}+\mathrm{X} \mathrm{\textrm {C } ^ { * } )}\right.
$$

And we have

$$
\mathrm{a}_{\mathrm{i}} \mathrm{B}+(\mathrm{h} \delta \mathrm{R} / 1-\delta)-\mathrm{D}_{1}\left(\mathrm{C}-\mathrm{C}^{*}\right)-\mathrm{D}_{2}{ }^{\prime}\left(\mathrm{l}_{0}-\mathrm{L}+\mathrm{X} \mathrm{C^{* }}\right) \mathrm{C}^{*} \geq 0
$$

We differentiate this with respect to $\mathrm{R}$ to obtain

$$
\left.(\mathrm{h} \delta / 1-\delta)-\mathrm{D}_{2}, \mathrm{X} \frac{d C *}{d R}+\mathrm{C} * \frac{d X}{d R}\right)
$$

We take the derivative of (6) with respect to $\mathrm{R}$ and then we could get

$$
-\mathrm{D}_{1}, \frac{d C *}{d R}=\mathrm{D}_{2},\left(\mathrm{X} \frac{d C *}{d R}+\mathrm{C}^{*} \frac{d X}{d R}\right)
$$

If $\frac{d C *}{d R}>0$, then we shall conclude that

$(\mathrm{h} \delta / 1-\delta)+\mathrm{D}_{1}, \frac{d C *}{d R} \mathrm{C}^{*}>0$

On the other hand, if $\frac{d C *}{d R}<0$, we shall have $\frac{d X}{d R}>0$.

We could clearly see that the investment will increase as a reaction to an increase in $\mathrm{R}$, which will deteriorate the efficiency for the whole company because given (7), if $\frac{d X}{d R}>0$, there will be $\frac{d C *}{d R}<0$. The manager will report a lower cost to disguise his rent which leads more cost by twisting the information.

In most cases, the manager will have the highest rent just before the board or the shareholder groups make their decisions. Under such circumstance, the financial information will be the least efficient to show the actual cost of corporate investment during that period.

\section{ConClusion}

The manager will have to please some substantial shareholders to get a better payoff and extend his position as incumbent. In this kind situation, if there is no clear audit and no intervention from the regulator, there shall be overinvestment for the whole company and this efficiency may prolong itself if the manager wishes to beat any potential challengers in the market of managers. On the other hand, once the regulator tries to intervene and there will be a cap for the manager, he will try to distort the information which may cause 
another kind of inefficiency. Besides, the cap will decrease the good part of corporate investment as a result of the manager's allocation policy. The manager will also increase the spending to keep his rent and by disguising it the efficiency of the whole company will deteriorate. There will be a trade-off between overinvestment and the opposite.

\section{REFERENCES}

[1] Robinson, J. A., and R. Torvik(2005) “ White Elephants,” Journal of public economies, 89:197-210J.
[2] Maskin,E., and J. Tirole(2014) "Pandering and Pork-Barrel Politics," Working Paper.

[3] Maskin.E., and J. Tirole(2007) "Public-Private Partnerships and Government Spending Limits,” International Journal of Industrial Organization, 26(2): 412-420..

[4] Hart, O., and J. Tirole (1988) "Contract Renegotiation and Coasian Dynamics," Review of Economic Studies, 55: 509-540

[5] Osband, K.(1989) “Optimal Forecasting Incentives,” Journal of Political Economy 97:1091-1112.

[6] Maskin,E.(1999) "Nash Equilibrium and Welfare Optimality," Review of Economic Studies, 66:23-38 